\title{
Immunohistochemical Evaluation of Giant Cell Tumor of Bone
}

\author{
Jianwen Huang ${ }^{1,3}$, Shiping $\mathrm{Hu}^{2}$, Peisheng Huang ${ }^{1}$, Nengmu Shi' ${ }^{2}$ Meiqin Gao ${ }^{1}$, \\ Masanori Saito ${ }^{3}$ and Masahiko Mori $^{3}$ \\ 'Department of Pathology, Fujian Medical College, Fuzhou, Fujian, P. R. of China, 'Department of Orthopedic \\ Surgery, Fujian Provincial Hospital, Fuzhou, Fujian, P. R. of China, ${ }^{3}$ Department of Oral and Maxillofacial \\ Surgery, Asahi University School of Dentistry, 1851-1, Hozumi, Hozumi-cho, Motosu-gun, Gifu 501-02
}

Received for publication March 27, 1996 and in revised form June 26, 1996

\begin{abstract}
Twenty seven cases of giant cell tumor of bone were evaluated for their cell kinetics by using proliferating cell nuclear antigen (PCNA) immunoreactivity and antiproteolytic and Iysozymal activities in multinucleated giant cells and mononuclear cells in order to evaluate their cellular characteristics and possible histogenesis. The multinucleated giant cell nuclei were unlabeled by PCNA and the major proliferating cells in the tumor were identified as mononuclear cells. No significant correlation existed between the PCNA labeling index and histopathological gradings of the giant cell tumors. Mononuclear cells were either fibroblast-like cells or histiocyte-like cells. The fibroblastlike cells showed an intense immunoreactivity for vimentin and PCNA whereas the histiocyte-like cells were intensely reactive for lysozyme, alpha-1 antitrypsin, alpha-1
\end{abstract}

antichymotrypsin. The multinucleated giant cells, on the other hand, more frequently showed immunoreactivity of lysozyme, alpha-1 antitrypsin, alpha-1 antichymotrypsin mimicing the profile of histiocyte-like cells. The results of the present study allowed us to reasonably conclude that the fibroblast-like cells were the major proliferating cells in the giant cell tumors which may originate from the mesenchymal fibroblasts; the multinucleated giant cells do not form a proliferating population of cells but may be a fusion product of histiocyte-like cells possibly derived from the mononuclear phagocyte system. The conventional histopathological grading of the giant cell tumors of bone do not correspond with the cell proliferation potential in the tumor as assessed by PCNA immunohistochemistry.

Key words: Giant cell tumor, Immunohistochemistry, PCNA, Mononuclear cell

\section{Introduction}

Giant cell tumors of bone, primarily a lesion affecting long bones, are rare tumors and a number of studies to differentiate these tumors from a diverse group of giant cell lesions of bones such as giant cell reparative granuloma and aneurysmal bone cysts have shown that a number of pathological, histomorphological and immunological features demonstrate a considerable overlap between these lesions $[7,12,18,25,26,28,36,38,40,41]$. Giant cell lesions, in patients with hyperparathyroidism and cherubism, are well defined entities in which the natural history and prognosis are predictable. The nature of

Correspondence to: Professor Masahiko Mori, Department of Oral and Maxillofacial Surgery, Asahi University School of Dentistry, 1851-1, Hozumi, Hozumi-cho, Motosu-gun, Gifu 501-02, Japan. other giant cell lesions, on the other hand, are uncertain and may demonstrate variable clinical and histopathological features and may tend to show benign to aggressive behavior, recurrence and not quite infrequently metastases.

Studies on the pathobiology of giant cell tumors may therefore provide a rational basis to understand or predict the clinical behavior and novel application of therapeutic regimens which at present confer a considerable dilemma in diagnosis and management. The histogenesis and pathological significance of giant cells in giant cell tumors are far from clear. Multinucleated giant cells have been suggested to arise from mononuclear cells [13, 16, 39], macrophages [17], osteoclasts [2] or form a mixed population of these cells.

The present study evaluates cell kinetics of giant cell tumors using proliferating cell nuclear antigen (PCNA), a 
marker of proliferating cells and the index of which correlates with the histological grade of various tumors [1] and growth fraction information obtained from flow cytometry and Ki-67 labeling index [8, 10, 23], and its possible correlation with the histopathological grades of giant cell tumors of bone. In addition, attempts have been made to distinguish multinucleated giant cells from mononuclear cells and to define their histogenesis by using a number of tissue markers, vimentin, a marker of mesenchymal cells and antiproteolytic and lysozymal activities using antibodies against alhpa-1 antitrypsin, alpha-1 antichymotrypsin, lysozyme and lactoferrin.

\section{Materials and Methods}

Formalin fixed-paraffin embedded surgical specimens (27 cases) of giant cell tumors of bone, including Grade I $(n=6)$, Grade I-II $(n=8)$, Grade II-III $(n=9)$ and Grade III $(n=1)$ were retrieved from the files of the Department of Pathology, Fujian Medical College, P. R. of China. Paraffin sections at $4 \mu \mathrm{m}$ mounted on uncoated glass slides were evaluated for the presence of PCNA, vimentin, alpha-1 antitrypsin (AT), alpha-1 antichymotrypsin (ACT), lysozyme, and lactoferrin using an avidin-biotincomplex immunoperoxidase method. The primary antibodies, the working concentration and their source are listed in Table 1.

Tissue sections were deparaffinized and rehydrated through graded alcohol. The sections were treated with methanol containing $0.03 \% \quad \mathrm{H}_{2} \mathrm{O}_{2}$ for $30 \mathrm{~min}$. After washing in phosphate buffered saline (PBS), normal swine or rabbit serum $(1: 20)$ was overlaid on the tissue section for $30 \mathrm{~min}$ to reduce the nonspecific background staining. Primary antibodies were applied for $1 \mathrm{hr}$ at room temperature. After three consecutive washes in PBS, the tissues were incubated with either biotinlated anti-mouse or anti-rabbit immunoglobulin fraction (Dako, Denmark, $1: 200$ ) for $30 \mathrm{~min}$ at room temperature. Following washing in PBS, Strept-AB complex (Dako, Denmark, $1: 500$ ) was applied for $30 \mathrm{~min}$ at room temperature. Finally, DAB was used for visualization of the reaction products. Control tissue sections were subjected to the same procedures as above, but the monoclonal or

Table 1. Source and working dilution of specific antibodies

\begin{tabular}{llcc}
\hline \multicolumn{2}{l}{ Primary Antibodies Against } & Dilution & Source \\
\hline Vimentin & (MoAb) & $1: 40$ & Dako, Denmark \\
Alpha-1 AT & (PoAb) & $1: 40$ & Dako, Denmark \\
Alpha-1 ACT & (PoAb) & $1: 40$ & Dako, Denmark \\
Lysozyme & (PoAb) & $1: 40$ & Dako, Denmark \\
Lactoferrin & (PoAb) & $1: 50$ & Dako, Denmark \\
PCNA & (MoAb) & $1: 50$ & Dako, Denmark \\
\hline
\end{tabular}

MoAb $=$ Monoclonal antibody, $\quad$ PoAb $=$ Polyclonal antibody polyclonal antibodies were replaced by PBS.

The extent of PCNA positivity in the tissue sections was evaluated by determining the positively stained nuclei present in at least 1000 cells including mononuclear and giant cells using a Nikon microscope (20 objective and $\times 10$ eye piece). The significance of PCNA positivity and tumor grades or sex was assesed using Student's t-test and the results were considered significant when $p<0.05$.

\section{Results}

\section{Histopathology}

The histological grading of GCTs in present study was based on Jaffe's histological grading system: 1) Grade I tumors: were the least aggressive showing no appreciable atypia of mononuclear cells with numerous giant cells. Though these cells were abundant, they were not densely aggregated. The mononuclear cells were predominantly spindle and ovoid shaped; 2) Grade II tumors: were somewhat heterogenetic, ranging from those in which the mononuclear cells showed only slight atypia to those in which the mononuclear cells had features of malignant cells. The monouclear cells were abundant and closely aggregated; 3) Grade III tumors: were frankly and obviously malignant, possessing a sarcomatous type of stroma. Their mononuclear cells were abundant, closely aggregated and tended to present an irregular whorled arrangement. The giant cells were small and less numerous. Moreover, numerous multinucleated giant cells had eosinophilic cytoplasm and pyknotic nuclei which included numerous lymphocytes and neutrophils, as necrotic multinucleated giant cells. There were two kinds of mononuclear cells. Firstly, the fibroblast-like cells that were oval or spindle shaped, and secondly histiocyte-like cells with angular and eosinophilic shape.

\section{Immunohistochemistry}

PCNA immunoreactivity was observed in all cases of GCTs, and the immunohistochemical expression was characteristicly different between multinucleated giant cells and mononuclear cells. Multinucleated giant cells were devoid of any positive PCNA staining. In general, fibroblast-like mononuclear cells were more often reactive than histiocyte-like mononuclear cells (Fig. 1A). The mean and SD of positive nuclei in various tumor grades are summarized in Table 2. The PCNA labelling index did not correlate with the histopathological grading and $P>0.05$.

A number of mononuclear cells showed intense immunoreactivity for vimentin. However, vimentin immunoreactivity was positive in a few multinucleated giant cells (Fig. 1-B, C, D).

Lysozyme immunoreactivity was found in all cases of giant cell tumor of bone. In general, histiocyte-like cells were more often reactive than fibroblast-like cells. Less than $50 \%$ of multinucleated giant cells showed moderate to intense reaction for lysozyme. The granular deposition 


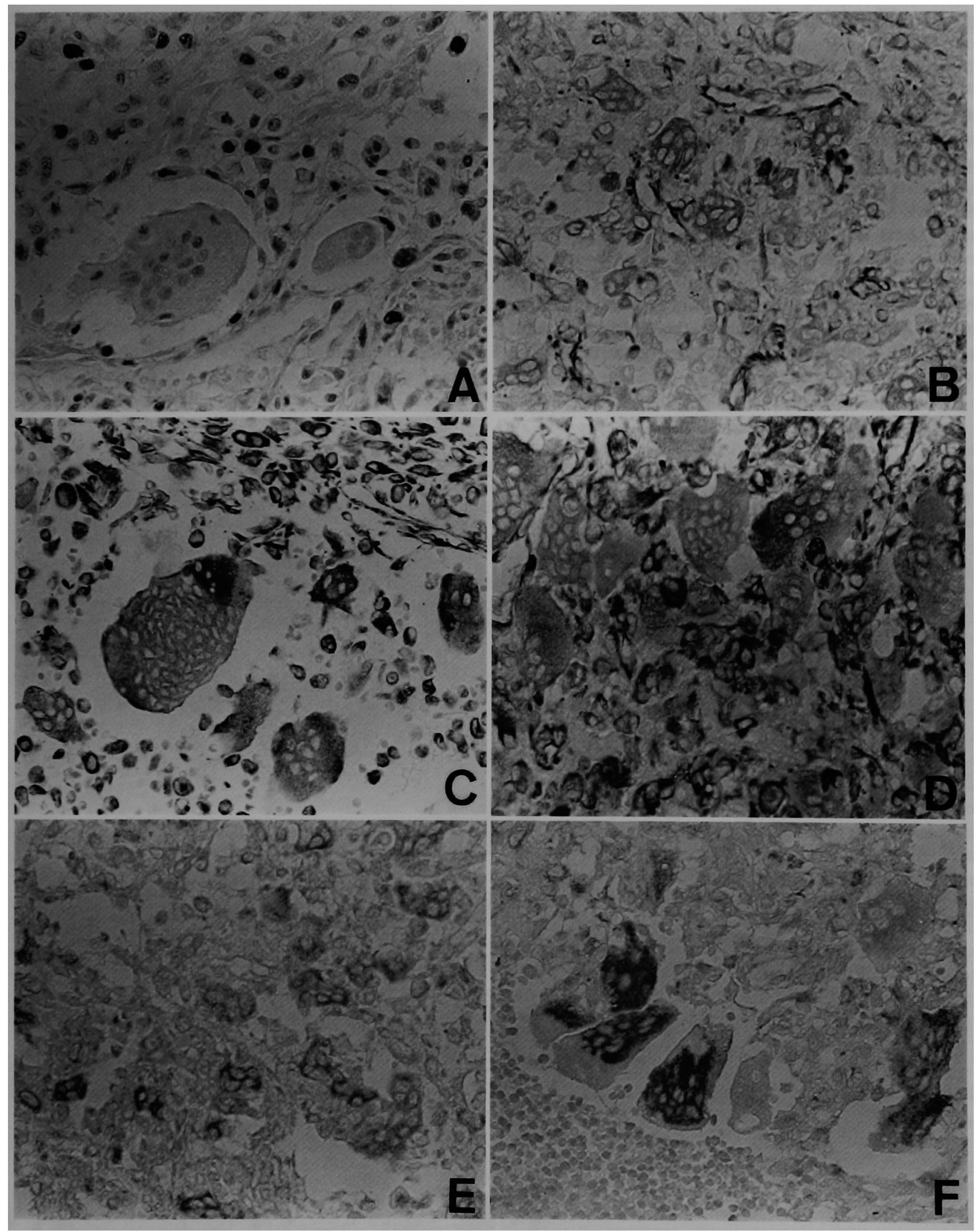

Fig. 1. A: Multinucleated giant cells are not labelled by PCNA, but mononuclear stromal cells show positive PCNA staining in nuclei. BD: Most mononuclear stromal cells and a few multinucleated giant cells showed intense immunoreactivity for vimentin. E: Lysozyme staining in cytoplasm of some mononuclear stromal cells. F: Multinucleated giant cells show intense immunoreactivity for lysozyme and the granular deposition of lysozyme is seen particularly in perinuclear area. $\times 200$. 
Table 2. Percentage of PCNA-positive mononuclear cells in different grade of GCTs

\begin{tabular}{lccc}
\hline \multicolumn{2}{c}{ Tumor Grade } & N & $\begin{array}{c}\text { \% PCNA positive nuclei } \\
\text { Mean standard deviation }\end{array}$ \\
\hline I & grade & 6 & $12.8 \pm 4.9$ \\
I-II & grade & 8 & $10.9 \pm 6.7$ \\
II & grade & 9 & $8.89 \pm 5.0$ \\
II-III & grade & 3 & $8.9 \pm 5.9$ \\
III & grade & 1 & 3.9 \\
\hline
\end{tabular}

of lysozyme was seen in the cytoplasm of multinucleated giant cells, particularly stronger in the perinuclear area (Fig. 1-E, F). Necrotic multinucleated giant cells were unreactive for lysozymes.
The alpha-1 antitrypsin and alpha- 1 antichymotrypsin immunoreactivities were heterogeneous, and some multinucleated giant cells showed intense immunoreactivity for alpha-1 antitrypsin and alpha-1 antichymotrypsin. Fine granular deposition in multinucleated giant cells cytoplasm was observed except for the perinuclear area. The histiocyte-like cells were more often positive than fibroblast-like cells (Fig. 2-A, B, C, D and Fig. 3-A, B, C).

Lactoferrin immunoreactivity was found in a few mononuclear cells and not in multinucleated giant cells.

Immunohistochemical results of GCT of bone are shown in Table 3.

\section{Discussion}

Cell kinetic information is becoming increasingly important as a potential prognostic indicator in cancer treat-

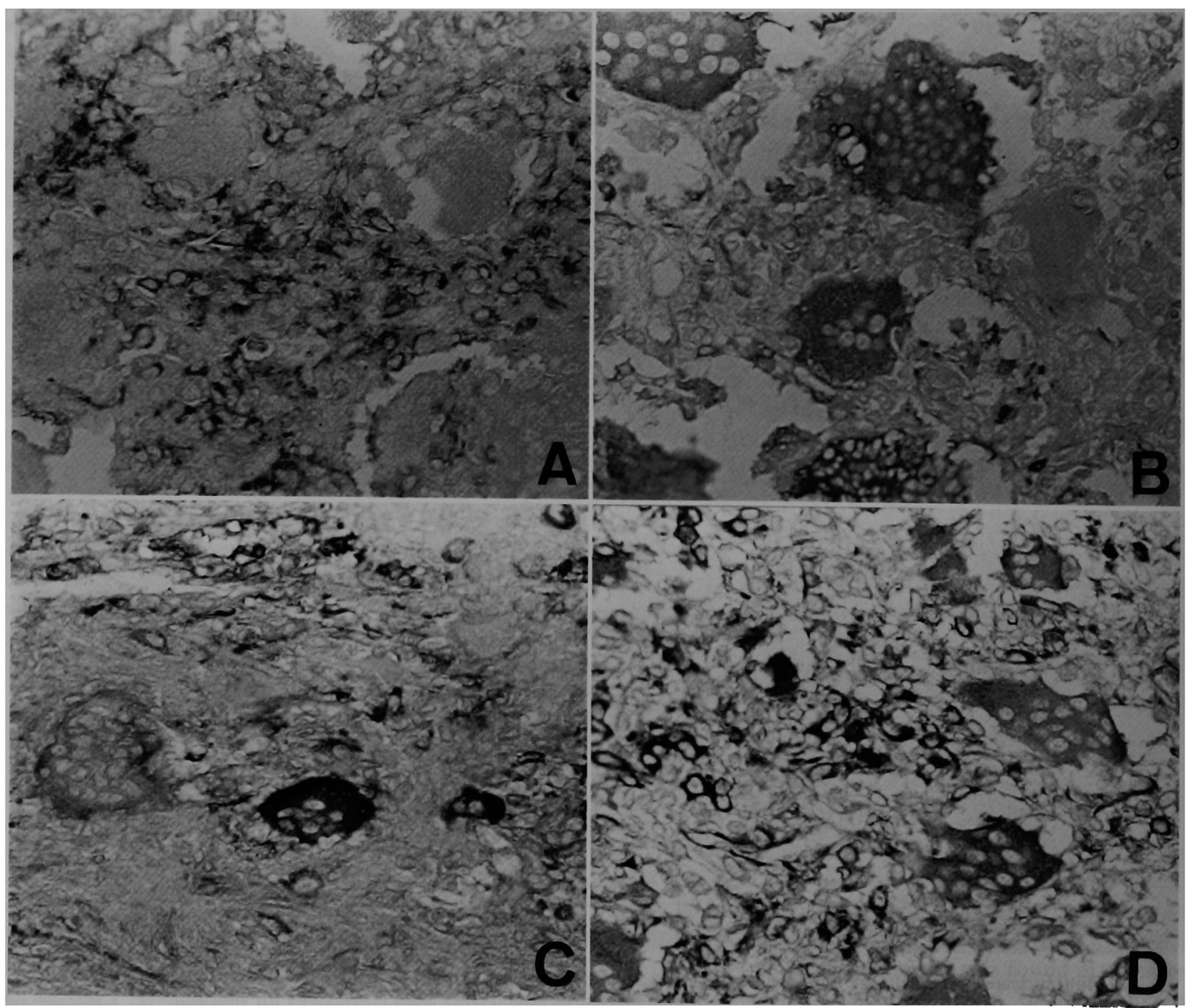

Fig. 2. A-D: Alpha-1 antitrypsin staining. Some multinucleated giant cells and mononuclear stromal cells showed moderate to intense immunoreactivity for alpha-1 antitrypsin and a fine granular deposition of reaction products in cytoplasm is observed except for perinuclear area. $\times 200$ 


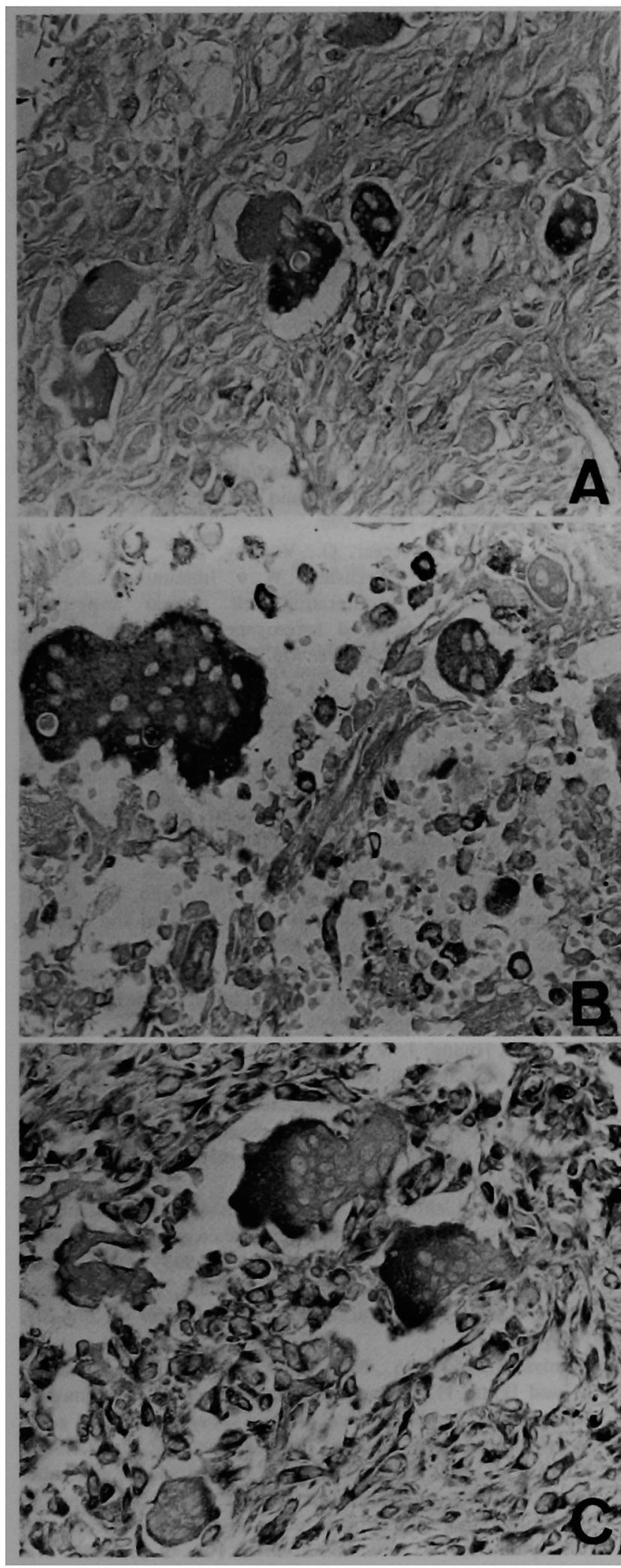

Fig. 3. A-C: Alpha-1 antichymotrypsin staining. Multinucleated giant cells and histiocyte-like stromal cells are intensely immunoreactive for alpha-1 antichymotrypsin. $\times 200$. ment and as a method for evaluating response to treatment $[3,6,11,30,31,37]$. Proliferating cell nuclear antigen (PCNA) is one such proliferation marker; a $36 \mathrm{KD}$ protein identified as an auxiliary protein of DNA polymerase [4]. Its distribution in the cell cycle, increasing through $G_{1}$, peaking at the $G_{1} / S$-phage interface, decreasing through $G_{2}$, and reaching low levels which are virtually undetectable by immunocytochemical methods in M-phase and quiescent cells, make it a useful marker for proliferating cells $[19,20,33]$. It has been reported that the PCNA labelling index correlates with histological grade [1] and with growth fraction data obtained using flow cytometry and the Ki67 labelling index $[8,10,23]$. However, numerous investigators have reported that the PCNA labelling index does not correlate with grading in breast cancers [22] and glioblastoma [9]. This is the first study of PCNA immunohistochemistry in giant cell tumor of bone. We found that giant cells are not labelled by PCNA, and it may be suggested that these giant cells do not undergo cellular division and the mononuclear cells were the major proliferating cells in GCT of bone. It has been accepted that histopathologic grading of giant cell tumor of bone by Jaffe not paralel for clinical behavers, and now we have not used such criteria of pathologic grading. We also found that there was no association between PCNA labelling index and histological grading devised by Jaffe. A number of investigators reported that histologic grade, based on variations of mononuclear and giant cells may not help predict the likelihood of recurrence of GCT $[12,21,32,40]$.

Lysozyme, alpha-1 antitrypsin and alpha-1 antichymotrypsin are usually regarded as enzyme markers for normal or reactive mononuclear macrophages. These lysozyme positive cells may be regarded as mature mononuclear macrophages and as representing an immunologic reaction of the host tissue against the tumor $[15,27,29,34]$. A population of multinucleated giant cells showed a similar profile of distribution of these markers suggesting them as fusion products of histiocytelike cells. Based on the results of the present study, on the basis of immunoreactivity of alpha-1 antitrypsin, alpha-1 antichymotrypsin and lysozyme, which are predominently in the histiocyte-like cells and to a lesser extent in the fibroblast-like cells, two populations of multinucleated giant cells, those with or without these markers may be encountered in GCT.

The mononuclear cells have been suggested to derive from the undifferentiated mesenchymal cells which then differentiate into osteoclasts [42], or the undifferentiated supporting connective tissue of bone marrow [24], the endothelial cells of blood vessels [35], or from histiocytes [5]. Analyzing the results of the present study and our previous report [14], we found that although giant cells showed heterogeneous immunoreactivity for vimentin, alpha-1 antitrypsin, alpha-1 antichymotrypsin and lysozyme, they showed uniformly intense immunoreactivity with monoclonal KP1 (CD 68) [14] and were unreactive 
Table 3. Immunohistochemical results of GCT of bone

\begin{tabular}{lcccccc}
\hline & Vim & AT & ACT & Lysozyme & Lactoferrin & PCNA \\
\hline Giant cells & + & $H$ & + & $H$ & - & - \\
Necrotic giant cells & - & - & - & - & - & - \\
Fibroblast-like cell & $H$ & + & + & + & $*$ & $H$ \\
Histiocyte-like cell & $H$ & $H$ & + & $H$ & $*$ & $H$ \\
\hline
\end{tabular}

$+=$ Less than $20 \%$ positive cells. $H=20-50 \%$ positive cells. $H=$ More than $50 \%$ positive cells

$*=\mathrm{A}$ few positive cells.

for PCNA. These findings suggested that giant cells may not be tumor cells and originate from mononuclear phagocyte system. The presence of necrostic giant cells led us to believe that giant cells were in the end stage of maturation and their ultimate fate is cell death. There are two types of mononuclear cells. One type of its cell termed fibroblast-like cells were predominently in the GCT of bone, and showed intense immunoreactivity for vimentin and PCNA but were unreactive or rarely reactive for alpha-1 antitrypsin, alpha-1 antichymotrypsin, lysozyme and KP1. They were real tumor cells and might originate from mesenchymal tissue. The other type of mononuclear cells termed histiocyte-like cells were in the minority and showed immunoreactivity for vimentin, alpha-1 antitrypsin, alpha-1 antichymotrypsin, lysozyme and KP1. They may originate from mononuclear phagocyte system and are precursors of giant cells.

\section{Acknowledgments}

The study was supported in part by Grant-in-Aid from Ministry of Eduction, Science and Culture (No. 07457499), Japan.

\section{References}

1. Allegranza, A., Girlando, S., Arrigoni, G. L., Veronese, S., Mauri, F. A., Gambacorta, M., Pollo, B., Dalla Palma, P. and Barbareschi, M.: Proliferating cell nuclear antigen expression in central nervous system neoplasms. Virchows Arch [A]. 419; 417-423, 1991.

2. Athanasou, N. A., Pringle, J.A.S., Revell, P.A. and Chambers, T. J.: Resorption of bone by human osteoclastoma cells. J. Pathol. 141; 508, 1983.

3. Bauer, K. D., Merkel, D. E., Winter, J. N., Marder, R. J., Hauck, W. W., Wallemark, C. B., Willimams, T. J. and Variakojis, D.: Prognostic implications of ploidy and proliferative activity in diffuse large cell lymphomas. Cancer Res. 46; 3173-3178, 1986.

4. Bravo, R., Frank, R., Blundell, P. A. and Macdonald, B. H.: Cyclin/PCNA is the auxiliary protein of DNA polymerasedelta. Nature 326; 515-523, 1987.

5. Brecher, A. M., Franklin, W. A. and Simon, M. A.: Immunohistochemical study of mononuclear phagocyte antigens in giant cell tumor of bone. Am. J. Pathol. 125; 252-257, 1986.

6. Costa, A., Bonadonna, G., Villa, E., Valagussa, P. and Silvestrini, R.: Labeling index as a prognostic marker in non-
Hodgkin's Lymphomas. J. Natl. Cancer Inst. 66; 1-5, 1981.

7. Dahlin, D. C., Cupps, R.E. and Johnson, E. W. Jr.: Giantcell tumor: A study of 195 cases. Cancer 25; 1061-1070, 1970.

8. Dawson, A. E., Norton, J. A. and Weinberg, D. S.: Comparative assessment of proliferation and DNA content in breast carcinoma by image analysis and flow cytometry. $A m$. J. Pathol. 136; 1115-1124, 1990.

9. Figge, C., Reinfenberger, G., Vogeley, K. T., Messing, M., Roosen, N. and Wechsler, W.: Immunohistochemical demonstration of proliferating cell nuclear antigen in glioblastomas: pronounced heterogeneity and lack of prognostic significance. J. Cancer Res. Clin. Oncol. 118; 289-295, 1992.

10. Garcia, R. L., Coltrera, M. D. and Gown, A.M.: Analysis of proliferative grade using anti-PCNA/cyclin monoclonal antibodies in fixed, embedded tissues. Am. J. Pathol. 134; 733-739, 1989.

11. Gentili, C., Sanfilippo, O. and Silvestrini, R.: Cell proliferation and its relationship to clinical features and relapse in breast cancers. Cancer 48; 974-979, 1981.

12. Goldenberg, R. R., Campbell, C. J. and Bonfiglio, M.: Giantcell tumor of bone. An analysis of two hundred and eighteen cases. J. Bone Joint Surg. 52; 619-664, 1970.

13. Hanaoka, H., Friedman, B. and Mack, R. P.: Ultrastructure and histogenesis of giant-cell tumor of bone. Cancer 25; 1408$1423,1970$.

14. Hu, S. P., Huang, J. W. and Gao, M. Q.: Analysis of cellular elements of giant cell tumor of bone using monoclonal KP antibody. J. of Fujian Medical College 29; 274-275, 1995.

15. Isaacson, P., Jones, D., Millward-Sadler, G., Judd, M. and Payne, S.: Alphal-antitrypsin in human macrophages. $J$. Clin. Pathol. 34; 982-999, 1981.

16. Jaffe, H. L., Lichtenstein, L. and Portis, R. B.: Giant cell tumor of bone. Its pathologic appearance, grading, supposed variants and treatment. Arch. Pathol. 30; 993-1002, 1940.

17. Kashara, K., Yamamuro, T. and Kashara, A.: Giant-cell tumor of bone: cytological studies. Br. J. Cancer 40; 201-209, 1979.

18. Komiya, S., Inoue, A., Nakashima, M., Ueno, A., Fujikawa, K. and Ikuta, H.: Prognostic factors in giant cell tumor of bone: A modified histological grading system useful as a guide to prognosis. Arch. Orthop. Trauma. Sur. 105; 67-72, 1986.

19. Kurki, P., Ogata, K. and Tan, E. M.: Monoclonal antibodies to proliferating cell nuclear antigen (PCNA)/cyclin as probes for proliferating cells by immunofluorescence microscopy and flow cytometry. J. Immunol. Methods 109; 49-59, 1988.

20. Kurki, P., Vanderlaan, M., Dolbeare, F., Gray, J. and Tan, E. M.: Expression of proliferating cell nuclear antigen (PCNA)/cyclin during the cell cycle. Exp. Cell Res. 166; 209$219,1986$.

21. Larsson, S. E., Lorentzon, R. and Boquist, L.: Giant-cell 
tumor of bone: a demographic, clinical, and histopathological study of all cases recorded in the Swidish Cancer Registry for the years 1958 through 1968. J. Bone Joint Surg. 57; 167-173, 1975.

22. Leonardi, E., Girlando, S., Serio, G., Mauri, F. A., Perrone, G., Scampini, S., Dalla Palma, P. and Barbareschi, M.: PCNA and Ki67 expression in breast carcinoma: Correlations with clinical and biological variables. J. Clin. Pathol. 45; 416$419,1992$.

23. Levison, D. A., Hall, P. A., Woods, A. L., Yu, C., Barnes, D. M., Wasseem, N. and Lane, D. P.: Evaluation of PCNA (proliferating cell nuclear antigen) immunostaining as a marker of cell proliferation in formalin-fixed paraffin-embedded tissues. J. Pathol. 161; 341, 1990.

24. Lichtenstein, L.: Bone Tumor. 3rd ed., CV Mosby Co., St. Louis. 1965.

25. Liu, T. C. and Luo, T. X.: Ultrastructure of giant cell tumor of bone. I. Classification of stromal cells and its correlation to grading. Chinese J. Orthop. 2; 205-207, 1982.

26. Luo, T. X. and Liu, T. C.: Ultrastructural observation on giant cell tumor of bone. II. Preliminary report on subtypes and origin of the multinucleate giant cells. Chinese J. Oncol. 5; 105-107, 1983.

27. Mason, D. and Taylor, C.: The distribution of muramidase (Lysozyme) in human tissue. J. Clin. Pathol. 28; 124-132, 1975.

28. Mellin, W., Roessner, A., Grundmann, E., Woermann, B., Hiddemann, W. and Immenkamp, M.: Biological characterization of human bone tumors. VII. Detection of malignancy in a giant cell tumor of bone by flow cytometric DNA-analysis. Path. Res. Pract. 180; 619-625, 1985.

29. Mendelshon, G., Eggleston, J. C. and Mann, R. B.: Relationship of lysozyme (muramidase) to histiocytic differentiation in malignant histiocytosis. Cancer 45; 273-279, 1980.

30. Meyer, J.S., Friedman, E., McCrate, M. M. and Bauer, W.C.: Prediction of early couse of breast carcinoma by thymidine labeling. Cancer 51; 1879-1886, 1983.

31. Meyer, J.S., Prey, M. U., Babcock, D.S. and McDivitt,
R. W.: Breast carcinoma cell kinetics, morphology, stage, and host characteristics. A thymidine labeling study. Lab. Invest. $54 ; 41-51,1986$.

32. Mirra, J. M.: Bone Tumors. Diagnosis and Treatment. Philadelphia: J. B. Lippincott 1980, pp. 344-349.

33. Morris, G. F. and Mathews, M. B.: Regulation of proliferating cell nuclear antigen during the cell cycle. J. Biol. Chem. 264; 13856-13864, 1989.

34. Motoi, M., Stein, H. and Lennert, K.: Demonstration of lysozyme, 1-antichymotrypsin, 1-antitrypsin, albumin, and transferrin with the immunoperoxidase method in lymph node cells. Virchows Arch. [B] 35; 73-82, 1980

35. Rather, L. J.: A note on the origin of multinucleated giant cell from vascular channels in tumors. Arch. Pathol. 52; 98-103, 1951.

36. Roessner, A., Bassewitz, D. B. V., Schlake, W., Thorwesten, G. and Grundmann, E.: Biologic characterization of human bone tumors. III. Giant cell tumor of bone. A combined electron microscopical, histochemical, and autoradiographical study. Path. Res. Pract. 178; 431-440, 1984.

37. Roos, G., Dige, U., Lenner, P., Lindh, J. and Johansson, H.: Prognostic significance of DNA-analysis by flow cytometry in non-Hodgkin's lymphoma. Hematol. Oncol. 3; 233-242, 1985.

38. Schajowicz, F.: Giant cell tumors of bone (osteoclastoma): A pathological and histochemical study. J. Bone Joint Surg. 43A; 1-29, 1961.

39. Steiner, G. C., Ghosh, L. and Dorfman, H. D.: Ultrastructure of giant-cell tumors of bone. Hum. Pathol. 3; 569-586, 1972.

40. Sung, H. W., Kuo, D. P., Shu, W. P., Chai, Y. B., Liu, C. C. and Li, S. M.: Giant-cell tumor of bone: Analysis of two hundred and eight cases in Chinese patients. J. Bone Joint Surg. 64A; 755-761, 1982.

41. Warshawsky, H., Goltzman, D., Rouleau, M. F. and Bergeron, J. J.: Direct in vivo demonstration by radioautography of specific binding sites for calcitonin in skeletal and renal tissues of the rat. J. Cell Biol. 85; 682-694, 1980.

42. Willis, R. A.: Pathology of Tumors. 4th ed., Butterworths \& Co., London, 1967. 